\title{
Literatura e política no Brasil (1870-1890): a atualidade do pensamento de Aluísio Azevedo
}

Laysi Praxedes Nobre

\section{Resumo:}

Contextualizando as duas principais obras de Aluísio Azevedo - O mulato e $O$ cortiço - no efervescente período político e intelectual de I870 a I890, a presente pesquisa busca apreender como o contexto social definiu um sentido à produção literária desse autor e, sobretudo, qual sentido determinou. Portanto, é pressuposto da análise o posicionamento político de Azevedo bem como sua experiência social, analisados através das charges e crônicas do autor. Palavras-chave: Literatura Brasileira - Política - Século XIX 
Literatura e política no Brasil (I870-I890): a atualidade do pensamento de Aluísio Azevedo

\section{Introdução}

Alguns intérpretes ${ }^{\mathrm{I}}$ do século XIX brasileiro, como Cruz Costa e Antonio Paim, estudaram a geração de I870 à luz das ideias europeias, então em voga. Assim, aproximaram as escolas de pensamento europeias - positivismo, cientificismo, darwinismo social etc. - da realidade brasileira, sem considerar o contexto político de apropriação de tais teorias. Segundo a socióloga Angela Alonso, em Ideias em movimento (2002), o contexto social dessa época selecionou, politicamente, as teorias europeias, resignificando tais filosofias com a realidade brasileira daquele momento. Com base nessa visão, pretende-se analisar as obras $O$ mulato (I88I) e $O$ cortiço (I890), de Aluísio Azevedo, procurando relacioná-las a outras produções intelectuais do autor, não muito estudadas, como charges e crônicas, e apreender a relação entre a arte literária e a experiência social.

Aluísio Azevedo, bem como Machado de Assis, Raul Pompeia e Olavo Bilac, é um exemplo de ficcionista que escreveu durante um período crucial de transição na política brasileira: a segunda metade do século XIX. Foi a partir de I870 que uma geração "intelectual”, heterogênea socialmente, levou adiante suas ações políticas contra o status quo imperial. De acordo com a socióloga Angela Alonso, essas ações mostravam-se na forma e no próprio ato de escrever. Ao estudar os textos e as práticas políticas dos membros dessa geração - como Quintino Bocaiúva, Joaquim Nabuco, Rui Barbosa, Clóvis Beviláqua, Sílvio Romero e muitos outros -, a autora chega à conclusão de que política e atividade intelectual eram indissociáveis na época: "Dada a inexistência de um campo intelectual autônomo no século XIX brasileiro, toda manifestação intelectual era imediatamente um evento político" (ALONSO 2002, p. 38).

Tal perspectiva traz uma mudança significativa nas análises das obras do período; assim, ao invés de estudar uma obra a partir dos conceitos das escolas europeias de pensamento da época, bem como através de como a obra capta a dinâmica social, a autora toma como ponto de partida a prática social dos autores em relação aos contextos da época, e não os sistemas de ideias, "como

\footnotetext{
I Muitos autores estudaram a geração de I870, como Faoro, Sérgio Buarque de Holanda e Florestan Fernandes, que compuseram obras de "interpretação do Brasil". Alonso (2002) agrupa os estudos dessa geração em duas vertentes, da teoria e da prática, enfatizando a História das Ideias como tendência de grande influência. Desse grupo, a autora ressalta Cruz Costa (I956) e Antonio Paim (I966), pois, embora distintos em muitos pontos, assemelham-se na forma em que analisam o período ao tratar a história da perspectiva das ideias em detrimento das práticas políticas.
} 
se eles tivessem vida própria" (id. ibid., p. 35). Esse posicionamento se opõe a muitos estudiosos do século XIX brasileiro, como Roberto Schwarz:

Schwarz (I989;1990) buscou uma mediação para as relações entre as ideias europeias e a realidade brasileira na experiência social brasileira. [...] Sua análise enfatiza a construção dinâmica de elos de deslocamento e acomodação entre ideias estrangeiras e sociedade nacional, amalgamados na própria estrutura da obra - literária, no caso [...]. A obra serve, pois, como instrumento heurístico na investigação de uma experiência social. Assim, Schwarz não considera a obra em seu contexto sociopolítico, preferindo analisar o modo pelo qual os textos machadianos desvelam a lógica sistêmica da sociedade escravista brasileira (id. ibid., pp. 34-35).

Dessa forma, Ideias em movimento posiciona-se na contramão de Schwarz, pois pretende "apreender o sentido que o contexto social confere à produção intelectual do período" e não "mostrar como uma obra captura a lógica da sociedade brasileira de fins do império" (id. ibid., p. 35). O presente trabalho, portanto, tem o mesmo intuito da socióloga, porém com o olhar voltado à literatura daquela época. Pretende-se verificar qual o sentido que a sociedade, a política e todo o contexto da geração de 1870 deram à obra do romancista Aluísio Azevedo. Para chegar a essa análise foi preciso estudar seus textos não literários, procurando um posicionamento político que poderia desvelar-se na produção ficcional. O encaminhamento dos estudos se deu com a leitura da biografia de Aluísio Azevedo, sobretudo suas crônicas para o jornal O Pensador. Depois, chegou-se à análise de dois romances centrais; um famoso por inaugurar a escola naturalista no Brasil ( $O$ mulato) e outro por consolidá-la ( $O$ cortiço $)$.

\section{Das charges às crônicas: os primeiros posicionamentos políticos de Aluísio Azevedo}

Desde muito novo Aluísio Azevedo se sensibilizava com as injustiças cometidas contra o negro em sua terra natal, São Luís do Maranhão. Como seus pais não tinham nenhum escravo, foi somente aos doze anos que ele veria uma cena de agressão que o marcaria para sempre. Tratava-se de um mulato, gemendo, preso em um tronco dentro de um quarto escuro do convento Nossa Senhora do Carmo. Anos mais tarde, em I88I, Aluísio Azevedo escreveria sobre o assunto no jornal $O$ Pensador: 


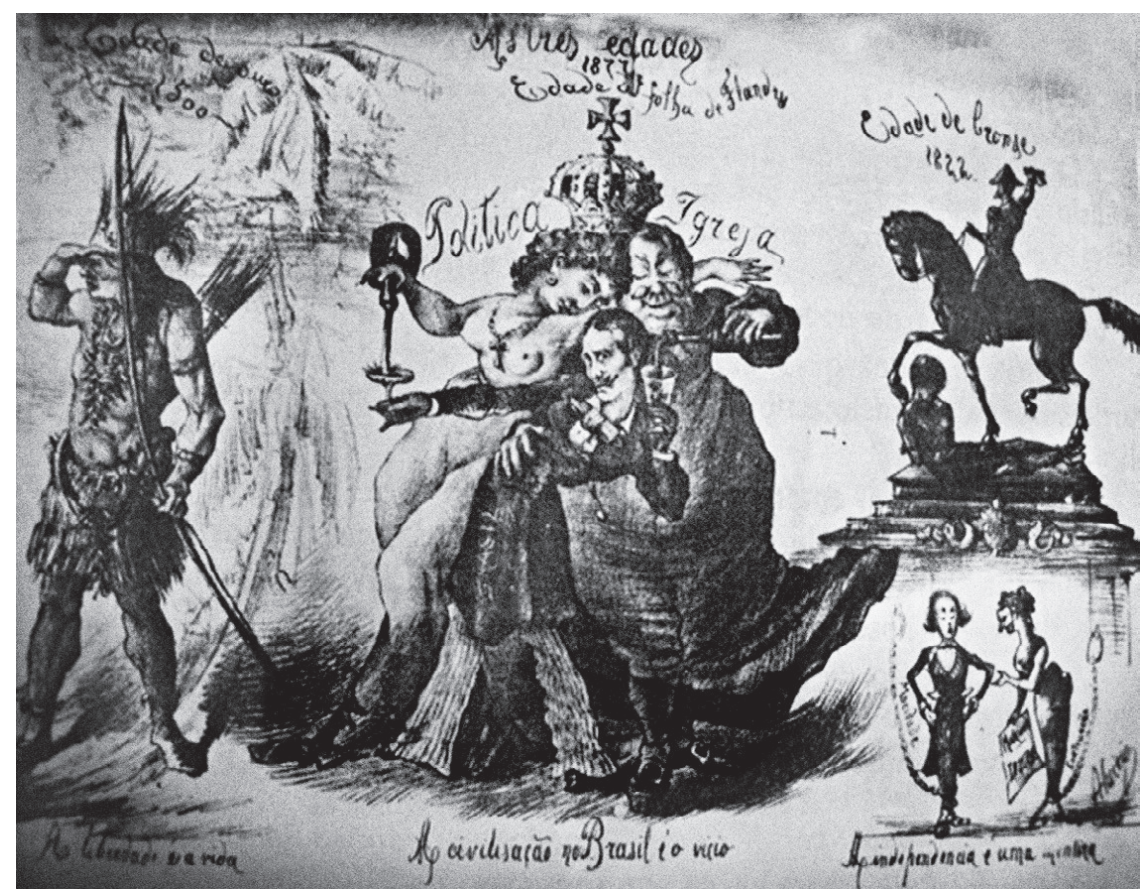

Figura I: As três idades do Brasil. Aluísio Azevedo. O Mequetrefe, Rio de Janeiro, n. 94, I9 mar. I877 (MÉRIAN I988, p.IIO).

pela primeira vez considerei minha pátria uma terra miserável; porque consentia, autorizava com uma lei escandalosa, o escravo. Já lá se vão doze anos e o escravo de Nossa Senhora do Carmo está vivo em minha memória como se eu o tivesse visto neste instante. Foi ele quem me despertou a primeira ideia de liberdade, devo talvez a esse desgraçado o grande ódio que voto hoje a tudo que é despótico e opressor (MÉRIAN I988, p. 48).

De acordo com Jean-Yves Mérian (I988), o romance $O$ mulato (I88I) se passa na mesma época desse acontecimento, revelando assim o tamanho da impressão que tal fato causou no romancista, que observaria e relataria outras cenas do mesmo teor em crônicas ou através de charges, sua primeira forma de expressão artística.

Assim, quando Aluísio Azevedo mudou-se pela primeira vez de São Luís do Maranhão para a então capital do Império brasileiro, o Rio de Janeiro, entre I876 e I878, não começou a escrever para os jornais da época, mas a desenhar. Suas charges revelavam sempre uma postura contrária às instâncias que legitimavam o Império brasileiro, como a escravidão, a Igreja e a figura do imperador. Em um de seus desenhos, intitulado As três idades do Brasil (figura I), nossa pátria é dividida em três momentos históricos distintos: a idade 
de ouro, representada por um índio antes da chegada dos portugueses; a idade de bronze, simbolizando o período da nossa Independência, vista como uma mentira; e, finalmente, a idade da folha de flandres, que seria correspondente ao período contemporâneo do autor. Na representação da contemporaneidade, o Brasil é um bêbado corrompido por uma prostituta, que representa a política, e um padre, que simboliza a Igreja. Em outra caricatura, o imperador é retratado fumando despreocupadamente, enquanto pela nuvem de fumaça de seu narguilé sai uma gama de problemas sociais brasileiros (id. ibid.).

$\mathrm{Na}$ grande maioria dessas charges o teor político prevalece, revelando uma análise crítica em forma pictórica do Brasil de I870. Na primeira charge, As três idades do Brasil, Aluísio Azevedo indicia uma postura favorável à concepção romântico-indianista de autoafirmação e recriação da nacionalidade brasileira por meio da idealização da figura indígena. Por isso, o autor considera como idade de ouro a época antes da chegada dos portugueses e o índio como representante máximo dessa época. Porém, a idealização para por aí. Diferente de românticos como José de Alencar, critica fortemente os portugueses, principalmente a figura do imperador, que é representada como indiferente às questões sociais que atormentam o país na época.

Se na charge a principal crítica era à política dos portugueses, com o povo brasileiro aparecendo oprimido e vítima do colonizador e das instâncias que legitimavam a monarquia, nas crônicas escritas para o jornal $O$ Pensador, entre I880 e I88I, o ataque principal de Aluísio Azevedo direcionou-se aos padres. Isso porque, após a publicação do livro 0 mulato, escrito entre o fim de I879 e o começo de I880, um grupo de jovens de São Luís resolveu criar um jornal anticlerical, nomeando-o de $O$ Pensador, e instaurando uma série de agressões à Igreja e à sociedade maranhense em geral. Como resposta, os padres lançam em seguida o jornal A Civilização, de teor religioso e ao mesmo tempo de ataque ao $O$ Pensador. Nessas circunstâncias, Aluísio Azevedo escreveu suas crônicas aqui resumidas.

As crônicas coletadas no livro Aluísio Azevedo e a polêmica d'O mulato (MONTELLO I975) dimensionam o pensamento do autor acerca de arte, religião e política. Sua percepção dos problemas sociais brasileiros aguça-se ainda mais sob tal modalidade de escrita, colocando a Igreja católica sob alvo permanente de ataque. Em um de seus escritos, polemiza sobre o padre:

O que são os padres? Em toda sociedade bem organizada a população se divide em dois grandes grupos - o grupo que trabalha e o grupo que devora. [...] Tudo o que há de mau, todos os vícios, todos os males sociais, todos os crimes vêm do grupo que não trabalha, do grupo que não produz. [...] Segue por conseguinte que a maldade está na razão direta da ociosidade. 
Literatura e política no Brasil (I870-I890): a atualidade do pensamento de Aluísio Azevedo

E qual o homem mais ocioso que há entre nós?

A resposta salta aos lábios - o padre!

Sim! O padre, esse que nada produz, esse que não faz o pão, como não faz um boneco, como não faz um livro que aproveite. [...] o padre não trabalha e quer que nós trabalhemos para encher-lhe o bandulho.

São muito ridículos! (id. ibid., pp. 223-27).

Sobressai-se no texto acima a crítica aos padres sob o pano de fundo de uma das temáticas positivistas - a valorização do trabalho. $\mathrm{O}$ autor usa desse pensamento filosófico universal para atacar um problema regional: o catolicismo, a religião de "Estado" que, junto com o indianismo romântico e o liberalismo estamental, justificava a política imperial brasileira (ALONSO 2002).

Essas teorias filosóficas vindas da Europa, como o positivismo, foram reajustadas à nossa realidade social para, de alguma forma, se opor ao status quo imperial (id. ibid.). Baseando-se no conceito sociológico de que "formas de pensar estão imersas em práticas e redes sociais" (id. ibid., p. 38), as esferas políticas e sociais não são separadas das da intelectualidade, nem as práticas dos autores ${ }^{2}$ brasileiros no século XIX de seus textos teóricos. Por conta disso, tais textos adquirem um significado de maior relevância se comparados com o contexto sociopolítico brasileiro daquela época em detrimento da equiparação com escolas europeias de pensamento e, assim, o que poderia ser uma cópia de conceitos estrangeiros obtém autonomia e renovação, já que a realidade local reajusta e transforma tais concepções filosóficas.

Sobre essa questão da imitação do modelo europeu, principalmente o francês, Aluísio Azevedo se manifesta através de suas crônicas. $\mathrm{O}$ autor pontua que não pretendia copiar, mas inspirar-se nele. A França seria o lugar em que brasileiros receberiam "inspiração e instrução", exercendo "um império inquestionável" sobre o Brasil e o resto do mundo, ponderava. Portanto, ver as coisas de um modo francês e imitar os franceses eram concepções que não andavam necessariamente juntas. Conclui que só chegaríamos a competir com aquele país "depois de possuirmos boa constituição, boa política, bom governo, boa família, boa sociedade, boa ciência, boa indústria, bons costumes e bom caráter". Só assim é que também alcançaríamos uma literatura de quali-

2 Esses autores estudados por Alonso, já citados anteriormente, são os membros da geração de I870. A socióloga os divide em: Liberais republicanos, Novos liberais, Positivistas abolicionistas, Federalistas positivistas do Rio Grande do Sul e Federalistas científicos de São Paulo. A socióloga não estuda nenhum autor ou texto literário. 


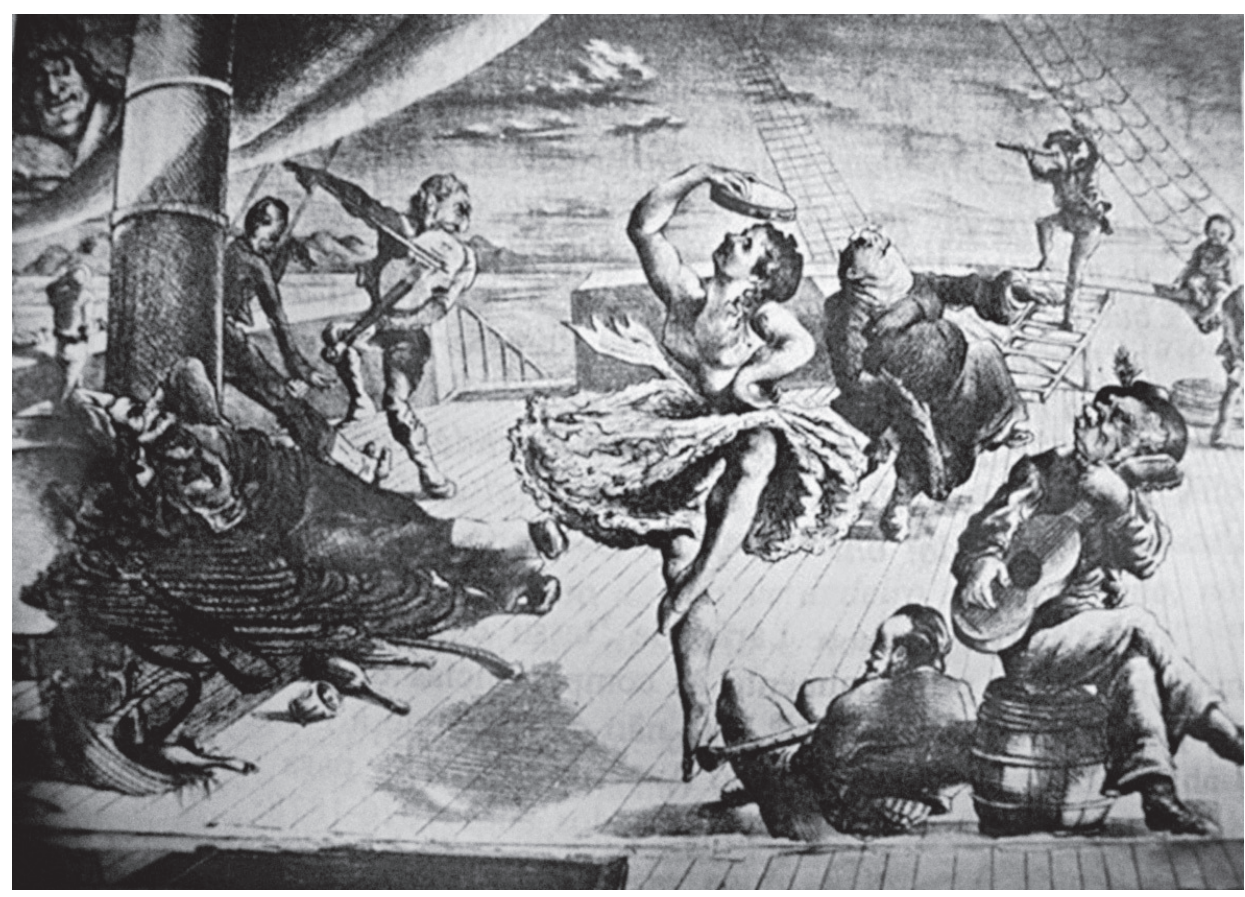

Figura 2: O Brasil à deriva. Aluísio Azevedo. O Mequetrefe, Rio de Janeiro, n. IO4, 27 jun. 1877 .

dade, "porque a literatura de qualquer país nunca foi senão a consequência de tudo isso". Ainda a respeito da literatura, acreditava que a literatura brasileira teria que se desprender da portuguesa e ser composta "em parte do português, em parte do tupi e em parte criada originalmente, de acordo com os nossos usos e costumes" (MONTELLO I975, pp. 95-99).

Tal comentário, além de revelar uma postura crítica à política brasileira, que culminará nos textos literários do autor, dando certo caráter de hibridismo a estes, pois ora estão mais ligados à tradição naturalista, ora recria um Naturalismo aos moldes brasileiros (CANDIDO 2004), também se associa à teoria de Angela Alonso na medida em que percebe que inspirar-se naquela poderosa nação não se revelaria necessariamente como uma cópia, mas uma inevitabilidade de todo século XIX. Ao afirmar que a literatura brasileira tinha de ser um todo que comportasse o português, o tupi e os usos e costumes da época, o autor faz um duplo movimento de voltar ao nosso passado histórico em busca de afirmar e entender o presente - assim como os românticos fizeram - e olhar o presente criticamente almejando um futuro diferente.

'Neste 'Barco Fantasma' que é o Brasil, o imperador cochila junto ao mastro. Os ministros tocam música (o Duque de Caxias, sentado num barril toca violão). 
Literatura e política no Brasil (I870-I890): a atualidade do pensamento de Aluísio Azevedo

Uma dançarina simboliza a política fútil do governo. O clero, sob os traços de um padre gordo, participa da festa. Enquanto isso, a Europa contempla a cena com interesse" (MÉRIAN I988, p. 508).

\section{Aproximação com a prosa alencariana e crítica social: hibridismo em $O$ mulato}

Tido como marco inaugural da literatura naturalista no Brasil, $O$ mulato (I88I) carrega em seu estilo composicional marcas de um hibridismo transitório entre características composicionais do romance alencariano e uma densa crítica à sociedade da época.

Assim, em um primeiro momento, o romance de Aluísio Azevedo trata a temática política com duras críticas às instâncias que legitimavam a ordem imperial brasileira: "o indianismo romântico, definindo a nacionalidade, o catolicismo, representando simbolicamente a sociedade hierárquica, o liberalismo estamental, limitando a cidadania" (ALONSO 200I, p. I68). Desse modo, é possível perceber, por meio da construção composicional das personagens e do romance, bem como dos diálogos, os posicionamentos ideológicos na narrativa. Um exemplo é a seguinte conversa:

- Não é para nossos beiços [a república], repito! Nós não estamos preparados para a república! O povo não tem instrução! É ignorante! é burro! não conhece seus direitos!

- Mas vem cá! replicou o Casusa, fechando no ar a sua mão pálida e encardida de cigarro. Diz você que o povo não tem instrução; muito bem! Mas, como quer que o povo seja instruído num país cuja riqueza se baseia na escravidão e com um sistema de governo que tira a sua vida justamente da ignorância das massas?... Por tal forma, nunca sairemos deste círculo vicioso! Não haverá república enquanto o povo for ignorante, ora, enquanto o governo for monárquico, conservará, por conveniência própria, a ignorância do povo; logo - nunca haverá república!

- E será o melhor!...

[...] E, chegando a boca a uma orelha do outro: - Olhe, meu Sebastião, aqui no Brasil vale mais a pena ser estrangeiro que filho da terra!... Você não está vendo todos os dias os nacionais perseguidos e desrespeitados, ao passo que os portugueses vão se enchendo, vão se enchendo, e as duas por três são comendadores, são barões, são tudo! Uma revolução! exclamou repelindo o Campos com ambas as mãos. Uma revolução é do que precisamos! (AZEVEDO, I996b, p.I84, cap. XIV). 
É notável no excerto acima uma predileção pelo discurso republicano em detrimento do monárquico-conservador. A narrativa se vale de tal artifício para demonstrar uma saída aos impasses que o romance vai colocando, principalmente na temática da escravidão. Além disso, a personagem ligada mais às ideias liberais defende, além da República, a federação, a revolução e critica os portugueses, ou seja, é contra o liberalismo imperial brasileiro que mantinha "o escravismo, a monarquia e a própria dominação senhorial" (ALONSO 2002, p. 59), estratificando ainda mais a sociedade.

Um dos principais focos da crítica em $O$ mulato é o catolicismo do Segundo Reinado, a religião de Estado, que legitimava a política imperial e hierarquizava a sociedade conforme a vontade divina (id. ibid.). Assim, não é à toa que o padre do romance é o assassino de dois personagens do livro - sendo um deles o próprio protagonista mulato que ascendia socialmente -, além de adúltero e reprodutor de ideias racistas como esta:

Pois você queria ver sua filha confessada, casada, por um negro? Você queria, seu Manuel, que a dona Anica beijasse a mão de um filho da Domingas [uma escrava]? Se você viesse a ter netos queria que eles apanhassem palmatoadas de um professor mais negro que esta botina? Ora, seu compadre, você às vezes até me parece tolo! (AZEVEDO ig96b, p. 30, cap. II).

Em um duplo movimento - de crítica à política e à religião que assegurava tal política -, O mulato mostra a hierarquização que o liberalismo imperial fazia, tendo como principal aliado o catolicismo; Raimundo chega ao topo da pirâmide de nossa sociedade estratificada, porém não se estabelece lá por completo, já que não consegue casar-se com uma branca. Sua morte, planejada por um padre, sinaliza as consequências perigosas dessa tentativa de mudança na sociedade brasileira. Apenas após uma revolução que tal hierarquia se dissiparia, como bem sugere o diálogo na página anterior entre as personagens Casusa e Sebastião.

Em um segundo momento, observa-se também uma aproximação formal com o romantismo alencariano. Raimundo, o mulato, é extremamente romantizado em suas características físicas (tem olhos azuis, quando hoje sabemos que isso não seria possível geneticamente) e psicológicas: "falava em voz baixa, distintamente, sem armar ao efeito; vestia-se com seriedade e bom gosto; amava as artes, as ciências, a literatura e, um pouco menos, a política” (id. ibid., p. 40, cap. III). Assim, Raimundo reunia todas as características de um herói romântico brasileiro; além da beleza, educou-se na Alemanha, França, Suíça e Estados Unidos. 
Literatura e política no Brasil (I870-I890): a atualidade do pensamento de Aluísio Azevedo

O mulato se aproxima da prosa de Alencar também pelas descrições românticas das personagens principais - o casal Raimundo e Ana Rosa - e do trato com o caso amoroso, permeado de diálogos teatrais. Um exemplo é quando Ana Rosa declara seu amor por Raimundo:

- A senhora não tem motivo para chorar!...

- Tenho, sim, respondeu ela por detrás do lenço.

- Ora essa! Então por que é?...

- É porque o amo muito, muito, entende? Declarou entre soluços, com os olhos fechados e gotejantes, e assoando-se devagarinho, sem afastar do nariz o lenço ensopado de lágrimas e entrouxado na mão - Desde que o vi! Desde o primeiro instante! Percebe? E no entanto meu primo nem...

E desatou a chorar mais forte ainda, desorientada, apaixonadamente (id. ibid., p. 30, cap. VI).

O capítulo do qual foi tirado o diálogo acima representa o teor dramático-teatral em que se encontra a descrição da relação amorosa entre o casal. De certo modo, esse capítulo lembra o famoso diálogo de Senhora (I875), quando Aurélia, ajoelhada, pede perdão a Seixas no último capítulo do romance alencariano. No entanto, Raimundo, diferente de Seixas que sucumbe ao amor de Aurélia, tendo os dois um final feliz, é um pouco menos afoito e, demonstrando sua "sobriedade" e "ética" europeias, trata o caso racionalmente; pede para que a moça saia de seu quarto, prometendo que se casará com ela. Assim, o final do romance é trágico para Raimundo e feliz para Ana Rosa. Ele é morto pelo padre e a moça, demonstrando frivolidade, casa-se rapidamente com outro rapaz, o que configura um final mais aos moldes realista/naturalista.

O romance carrega, então, esse hibridismo, em denunciar a política de seu tempo, com passagens naturalistas, e ainda estar apegado à tradição literária nacional de José de Alencar. Tal movimento contrastante acompanha toda a narrativa. Um exemplo foi notado na descrição que o autor faz de São Luís do Maranhão no começo do romance e no sétimo capítulo. Lê-se: "Era um dia abafadiço e aborrecido. A pobre cidade de São Luís do Maranhão parecia entorpecida pelo calor. [...] Em certos pontos não se encontrava viva alma na rua; tudo estava concentrado, adormecido; só os pretos faziam as compras para o jantar ou andavam no ganho" (id. ibid., p. I5, cap. I). "Adormecimento" sintetiza bem a concepção da política brasileira que a narrativa sugere. Eis, agora, como se introduz o sétimo capítulo: "Junho chegou, com as suas manhãs muito claras e muito brasileiras. 
É o mês mais bonito do Maranhão. Aparecem os primeiros ventos gerais, doidamente, que nem um bando solto de demônios travessos e brincalhões” (id. ibid., p. IOI, cap. VII).

A descrição da natureza adquire vigor e naturalismo quando se está sob o forte efeito do sol. Já no inverno, a descrição é mais amena e romântica, acompanhando a característica da estação, embora Naturalismo e Romantismo se misturem, talvez criando outra categorização literária. O que se evidencia também é que as mesmas características climáticas de São Luís do Maranhão podem ser atribuídas ao Brasil e sua população: "doidamente", "demônios travessos e brincalhões" compõem adjetivações da natureza como justificativa comportamental da população brasileira; ao mesmo tempo em que a natureza torna-se determinista, o resultado das mazelas brasileiras é equacionado de forma mais ampla e densa em $O$ mulato.

Assim, concernente ao romance $O$ mulato e se embasando por um olhar histórico-social da tese Ideias em movimento, de Angela Alonso (2002), notou- se como o contexto social brasileiro de 1870 determinou um sentido crítico à política imperial nesse romance, bem como a influência da tradição literária brasileira romântica, colocando o romance além da denominação "naturalista".

\section{IV. “E o povo... o povo também é rei. É rei como Jesus! Para beber o fel, para morrer na cruz": O cortiço (1890)}

Como a fotografia que perpassa a subjetividade do olhar do fotógrafo, sem deixar de revelar importantes aspectos da realidade exterior, a literatura de Aluísio Azevedo também se desloca por esse filtro do "eu", indivíduo produtor da arte, mas sem deixar de expor vertentes da realidade social brasileira de fins do século XIX. Nesse sentido, seu romance mais famoso e talvez o melhor realizado, O cortiço (I89o), torna-se exemplo de como o contexto social reverbera na arte literária.

Se em seu primeiro romance "naturalista" a personagem principal, que dá título ao livro, é o mulato Raimundo, agora a personagem principal é um cortiço, "filho" de uma escrava, Bertoleza, e do português João Romão. Assim, durante a narrativa, não só é relatada a ascensão financeira de João Romão, mas também o nascimento, o desenvolvimento e a transformação que se opera no cortiço.

O modo que a narrativa é construída remete a uma noção de acúmulo e ascensão: 
Literatura e política no Brasil (I870-I890): a atualidade do pensamento de Aluísio Azevedo

João Romão tornou-se o caixa, o procurador e o conselheiro da crioula. [...] E por tal forma foi o taverneiro ganhando confiança no espírito da mulher, que esta afinal nada mais resolvia só por si, e aceitava dele, cegamente, todo e qualquer arbítrio. Por último, se alguém precisava tratar com ela qualquer negócio, nem mais se dava ao trabalho de procurá-la, ia direto a João Romão (AZEVEDO I996a, p. I6, cap. I).

Além de confirmar a hipótese de uma linguagem de acúmulo, nota-se, no excerto, que Bertoleza saiu de um estado de escravidão formal para um informal. A escrava "forra", amante de João Romão, resigna-se diante do branco, sentindo uma necessidade instintiva de ser comandada por um, por isso é submetida à escravidão novamente. $\mathrm{O}$ romance critica então o modo instintivo de agir, que levará outras personagens à ruína, como o português Jerônimo, e também a forma de enriquecer ou ascender socialmente na época; através da escravidão de outro ser humano, do roubo e da avareza. São de tais atos que nascem o cortiço, ou seja, de uma política que permitia tais atrocidades nascia as condições para os problemas sociais brasileiros se desenvolverem. Nesse sentido está a alegoria do cortiço como o Brasil; nascido de um português corrupto (João Romão) e da escravidão (Bertoleza) e desenvolvido em um meio político-econômico de fins do século XIX que propiciava o roubo e a exploração.

As personagens do cortiço representam instâncias da sociedade brasileira da época. Por exemplo, o velho Botelho, parasita que morava na casa do português Miranda, seria a política escravocrata do antigo regime:

Assim, eram às vezes muito quentes as sobremesas do Miranda, quando, entre outros assuntos palpitantes, vinha à discussão o movimento abolicionista que principiava a formar-se em torno da lei Rio Branco. Então o Botelho ficava possesso e vomitava frases terríveis, para a direita e para a esquerda, como quem dispara tiros sem fazer alvo, e vociferava imprecações, aproveitando aquela válvula para desafogar o velho ódio acumulado dentro dele.

- Bandidos! Berrava apoplético. Cáfila de salteadores! (Id. ibid., pp. 30-3I, cap. II).

Já Miranda representa o português frustrado por não conseguir ser um rico explorador. Ao comprar um título de barão, prática comum da época, consolida uma personalidade que vive das aparências. A mulata Rita Baiana é responsável pela destruição da família de Jerônimo, português vencido pelo meio, instituição que era uma das principais bases positivistas. Além disso, como bem pontuou Antonio Candido (2004), Rita representa o pecado da terra, assemelhando-se nesse sentido à Iracema, de José de Alencar. A lingua- 
gem para descrever Rita Baiana oscila entre o Romantismo e o Naturalismo, como demonstra o seguinte excerto:

Naquela mulata estava o grande mistério, a síntese das impressões que ele recebeu chegando aqui: ela era a luz ardente do meio-dia; ela era o calor vermelho das sestas da fazenda; era o aroma quente dos trevos e das baunilhas, o que o atordoara nas matas brasileiras, era a palmeira virginal e esquiva que se não torce a nenhuma planta; era o veneno e era o açúcar gostoso; era o sapoti mais doce que o mel e era a castanha do caju, que abre feridas com o seu azeite de fogo; ela era a cobra verde e traiçoeira, a lagarta viscosa, a muriçoca doida, que esvoaçava havia muito tempo torno do corpo dele, assanhando-lhe os desejos, acordando-lhe as fibras embambecidas pela saudade da terra, picando-lhe as artérias, para lhe cuspir dentro do sangue uma centelha daquele amor setentrional, uma nota daquela música feita de gemidos de prazer, uma larva daquela nuvem de cantáridas que zumbiam em torno de Rita Baiana e espalhavam-se pelo ar numa fosforescência afrodisíaca (AZEVEDO ig96b, p. 73, cap. VII).

Outra personagem que remete à Alencar é Bertoleza, que tem traços da escrava Joana, da peça teatral Mãe. Quando João Romão critica o senhor que escravizava Bertoleza, essa responde: "Coitado! A gente se queixa é da sorte! Ele, como meu senhor, exigia o jornal, exigia o que era seu!" (id. ibid., p. I7, cap. I).

É possível, portanto, incluir Aluísio Azevedo em uma tradição literária nacional pela continuação de certos aspectos encontrados na obra de José de Alencar. Seja em sua trajetória pessoal, de atuação política, ou na obra literária - no que concerne especificamente a $O$ mulato e $O$ cortiço -, o autor demonstra que sua preocupação com a realidade social e política brasileira sucede uma suposta adesão ideológica à escola europeia tida como naturalista. Sua escrita adveio mais de uma preocupação local com a política centralizadora e hierarquizante do Império brasileiro do que apenas uma postulação estético-literária de bases naturalistas e positivistas. Essas correntes, antes de tudo, eram tidas como instrumentos de mudança da realidade brasileira pré-republicana e, quando incorporadas à nossa realidade, adquirem outra formalização estética.

Este trabalho procurou mostrar como os textos de Aluísio Azevedo apontaram para uma reflexão política; embora continuem em alguns aspectos ligados à tradição nacional de José de Alencar - na descrição, nos diálogos teatrais -, os romances são permeados de crítica às instâncias que legitimavam o Império. A obra de Aluísio Azevedo, tanto nas charges e nas crônicas quanto nos romances, liga-se, assim, à temática da geração de I870, descrita por Angela Alonso. Essa geração se apropriou de ideias europeias não para construir 
Literatura e política no Brasil (I870-I890): a atualidade do pensamento de Aluísio Azevedo

"teorias em meio a um debate intelectual abstrato", mas os repertórios teóricos foram "assimilados criteriosamente, conforme sua capacidade de elucidar a conjuntura brasileira e oferecer armas para a luta política" (ALONSO 2002, p. 332). A razão da busca por determinados elementos estrangeiros no Brasil do século XIX foi política (id. ibid.). "Nesse sentindo, não foram as ideias que buscaram um lugar, foi o lugar que requisitou, demarcou e explicou as ideias" (id. ibid., p. 339). Por isso, o naturalismo de Azevedo difere do de Émile Zola, por exemplo. O sentido social e político está presente desde os elementos formais da narrativa, por exemplo a linguagem que remete ao acúmulo de capital, em $O$ cortiço, até a temática contrária à monarquia, como a escravidão e a crítica ao clero em $O$ mulato. Dessa forma, o positivismo e o Naturalismo em sua obra eram usados para contestar o status quo imperial, ligando-se a uma demanda local brasileira, que resultaria mais tarde em nossa Primeira República (I889-I930).

\section{Referências bibliográficas}

ALONSO, Angela. Ideias em movimento: a geração I870 na crise do Brasil-Império. São Paulo: Paz e Terra, 2002.

AZEVEDO, Aluísio. O cortiço. São Paulo: Ática, I996a. O mulato. São Paulo: Ática, I996b.

CANDIDO, Antonio. De cortiço a cortiço. In: . O discurso e a cidade. São Paulo: Duas Gidades, 2004 .

GARVALHO, José Murilo de. A formação das almas: o imaginário da República no Brasil. São Paulo: Companhia das Letras, I990.

MÉRIAN, Jean-Yves. Aluísio Azevedo: vida e obra (I857-I9I3). Rio de Janeiro: Espaço e Tempo, I988.

MONTELLO, Josué. Aluísio Azevedo e a polêmica d'O mulato. Rio de Janeiro: José Olympio, I975.

Laysi Praxedes Nobre - Letras Bacharelado e Licenciatura em português/inglês (bacharelado concluído e licenciatura em andamento) pela Universidade de São Paulo. laysi.nobre@usp.br 